\title{
Uses of blockchain technologies in library services
}

\section{Hussain Abid}

\section{Introduction}

Blockchain is a new and reliable technology that helps with security, preservation and reliability of data. Libraries are change agents of the $21 \mathrm{st}$ century and are implementing new technologies to provide maximal information in minimal time. Blockchain technology can be used to solve different problems in library field with proper usages for storing information in a distributed temperresistant setting. Blockchain in library settings can be used to gather, preserve and share authoritative information devoid of many technological hurdles. Some challenges such as finance, technical and security issues are troubling factors, but proper training, support from decision makers and technical skills regarding this technology will pave the way for library practitioners. Undoubtedly, libraries are changing agents of the 21 st century and are working for the goodwill of the communities (Sharma and Batth, 2020). Blockchain technology is broadly based on distributed ledger technology (DLT), technology that records transactions with an immutable cryptographic signature named hash (Hussain, 2020). Figure 1 shows the structure of DLT in detail (Figures 1-3).

\section{Characteristic of blockchain technologies}

Some key characteristic of blockchain technologies are listed as follows:

- Increased capacity: Blockchain technology can increase the capacity of an entire network. One such example is supercomputer created by Stanford University used for medical research (Babich and Hilary, 2018).

- Better security: Blockchain technology offers better security as it provides for a network of

Figure 1. Properties of distributed ledger technology (DLT)

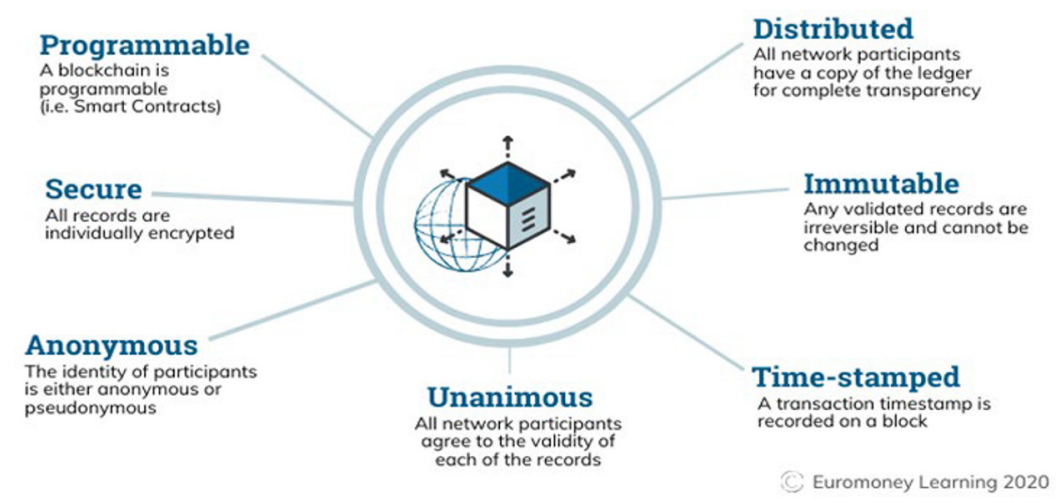

Source: Available at: www.euromoney.com/learning/Blockchain-explained/whatis-Blockchain

Figure 2. Characteristics of blockchain technologies

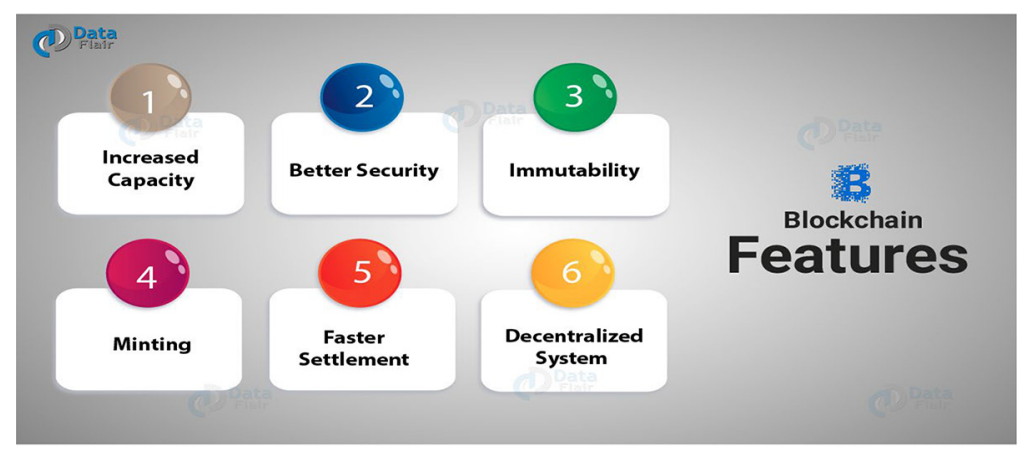

Source: Available at: https://data-flair.training/blogs/features-of-Blockchain

numerous computer nodes that can be used for networking transactions (Ahram et al., 2017).

- Immutability: Blockchain uses immutable ledgers, and all databases require trust of a third party to keep them secure from hackers. Blockchain applications, such as Bitcoin, maintain the ledger in a never-ending state of forward momentum.

- Faster settlement: Blockchain technology relies on faster speeds and saves time for institutions and consumers. One example from banking is that blockchain makes money transfer fast and convenient.

- Decentralized System: Blockchain technology offers a decentralized system that stores the assets in a network and can be accessed via the internet. The asset may be a contract or document of importance. The manager of blockchain technology has control 
Figure 3. Blockchain in library services

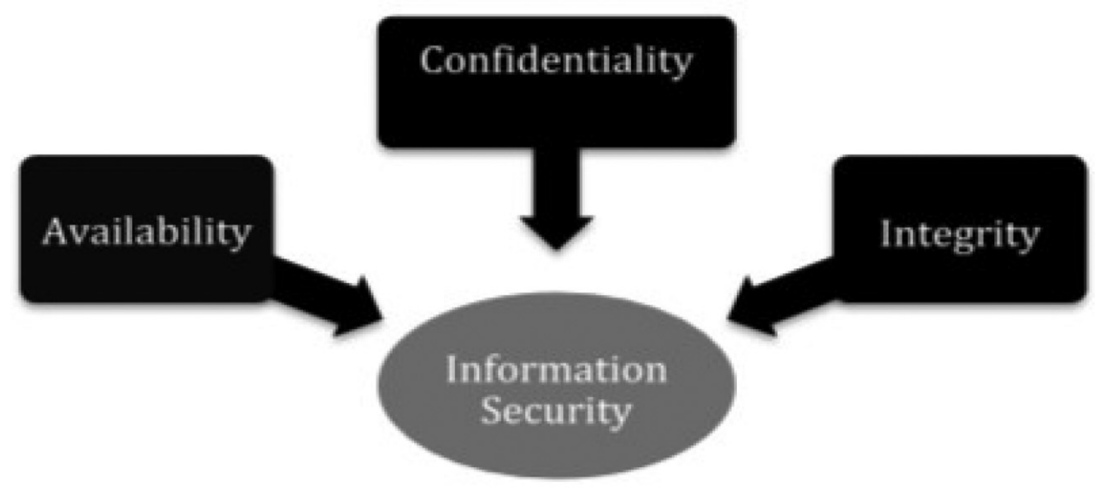

Source: Available at: www.ala.org/tools/article/future-libraries/Blockchain-and-futurelibraries-interview-sandra-hirsh-and-susan-alman

over account of individuals and can transfer anything to anyone. This technology is proving to be an effective tool for decentralizing the web (Jin et al., 2017).

- Minting: Blockchain technology involves minting a problem in several ways. Proof of work is one approach guaranteeing an individual is engaged in a significant amount of computation work.

\section{Blockchain implications for librarians}

Innovative technologies have brought enormous challenges for education and library services (Hussain, 2018). Librarians and information specialists are well-aware of technology needs for various library settings or for library users. Any new technology requires a hefty budget. Quite often, keeping abreast of new technologies is an uphill battle (Orick, 2000). Innovative new library responsibilities will also be useful for library administrators and students seeking a technology-oriented or curriculum-design career path in libraries.

Blockchain technology is basically storing information in a distributed temper-resistant setting. An ideal application of blockchain technology is preserving scientific publications published around the world. Using blockchain to store information was tested by Irving and Holden, who used low-cost verifiable methods for scientific literature by implementing Bitcoin blockchain technology for audit purposes.

Digital rights management connects libraries to pave the way for digital resources in libraries. Blockchain creates a unique verifiable record that can be accessed by anyone from anywhere.

Selected potential use cases for blockchain by libraries: Digital preservation and tracking; communitybased collections to share objects, tools and services; blockchain-based currencies for international financial transactions; inter library loan and voucher systems; library verification of credentialing (information literacy); library cards; archives/special collections where provenance and authenticity are essential; corporate library record keeping; and organizational data management of intellectual property for R\&D.

Concluding remarks: Factors involved in implementing blockchain in your libraries:

- Project management: There are different factors which should be kept in mind while launching blockchain projects such as programmers, project management team and visionary staff from your libraries.

- Resources and finance: Before launching blockchain technology, proper resources and finances are required. A blockchain solution for data alignment might be affordable and feasible if libraries have sufficient funds for the project.
- Problem solutions: Before implementing blockchain technology, librarians might keep the solution to each problem in mind, librarians should train people inside instead of relying on third parties. Keep private or sensitive data secure with the help of decentralized mechanisms (Carrie, 2019).

Blockchain technology is rapidly growing and evolving. Librarians need to understand blockchain's capabilities, benefits and risks. Perhaps blockchain technology in libraries will be useful tools for storing, preserving and sharing information. This technology will also be useful for the acquisition of library material that can improve collection maintenance. Blockchain can secure the record of users and patrons and to advance privacy of users and research data. Blockchain technology also increases collaboration between users and library professionals.

\section{REFERENCES}

Ahram, T., Sargolzaei, A., Sargolzaei, S., Daniels, J. and Amaba, B. (2017), "Blockchain technology innovations", 2017 IEEE Technology \& Engineering Management Conference (TEMSCON), IEEE, 137-141.

Babich, V. and Hilary, G. (2018), "What operations management researchers should know about blockchain technology", Georgetown Working Paper.

Big Data in Library Services | Daily times (2021), available at: https://dailytimes.com. pk/533352/big-data-in-library-servicesdaily-times/

Carrie, S. (2019), "Blockchain reaction”, from American Libraries Magazine website, available at: https://americanlibrariesmagazine. org/2019/03/01/library-Blockchain-reaction/ (accessed 18 August 2020).

Frederick, D.E. (2019), "Blockchain, libraries and the data deluge", Library $\mathrm{Hi}$ Tech News, Vol. 36 No. 10, pp. 1-7.

Hussain, A. (2018), “Awareness of web 2.0 technology in the academic libraries: an Islamabad perspective", Library Philosophy and Practice (e-Journal), available at: https:// digitalcommons.unl.edu/libphilprac/1945

Hussain, A. (2020), "Cutting edge: technology's impact on library services", Innovations in the Designing and Marketing of Information Services, IGI Global, pp. 16-27. 
Hussain, A. (2020), "Industrial revolution 4.0: implication to libraries and librarians | Emerald Insight", available at: www. emerald.com/insight/content/doi/10.1108/ LHTN-05-2019-0033/full/html (accessed 18 August 2020).

Jin, T., Zhang, X., Liu, Y. and Lei, K. (2017), "BlockNDN: a bitcoin blockchain decentralized system over named data networking", 2017 Ninth International Conference on Ubiquitous and Future Networks (ICUFN), IEEE, 75-80.

Orick, J.T. (2000), “The virtual library: changing roles and ethical challenges for librarians", International Information \& Library Review, Vol. 32 No. 3-4, pp. 313-324.

Sharma, S. and Batth, R.S. (2020), "Blockchain technology for higher education system: a mirror review", 2020 International Conference on Intelligent Engineering and Management (ICIEM), IEEE, 348-353.

\section{FURTHER READING}

Frederick, D.E. (2019), "Blockchain, libraries and the data deluge", Library $\mathrm{Hi}$ Tech News, Vol. 36 No. 10, pp. 1-7.

Hussain, A. and Jan, S.U. (2018), “User perception on electronic resources and services in national defense university library Islamabad", Pakistan, Pakistan Library \& Information Science Journal, Vol. 49 No. 3.

Irving, G. and Holden, J. (2016), "How blockchain-timestamped protocols could improve the trustworthiness of medical science", F1000Research, 5.

Meth, M. (2020), "Understanding blockchain", from American Libraries Magazine website, available at: https:// americanlibrariesmagazine.org/2020/01/02/ understanding-Blockchain-libraries/ (accessed 12 August 2020).
Team, D. (2018), "6 Major features of blockchain | why blockchain is popular?", from DataFlair website, available at: https:// data-flair.training/blogs/features-of-Blockchain/ (accessed 18 August 2020).

Zhang, L. (2019), "Blockchain: the new technology and its applications for libraries", Journal of Electronic Resources Librarianship, Vol. 31 No. 4, pp. 278-280.

Abid Hussain (abidmardan@gmail. com) is based at Institute of Strategic Studies Islamabad, Islamabad, Pakistan. 